\title{
Human Lung Cancer Cell Line A-549 ATCC Is Differentially Affected by Supranutritional Organic and Inorganic Selenium
}

\author{
Lérida Liss Flores Villavicencio, ${ }^{1}$ Gustavo Cruz-Jiménez, ${ }^{1}$ \\ Gloria Barbosa-Sabanero, ${ }^{1}$ Carlos Kornhauser-Araujo, ${ }^{1}$ M. Eugenia Mendoza-Garrido, ${ }^{2}$ \\ Guadalupe de la Rosa, ${ }^{1}$ and Myrna Sabanero-López ${ }^{1}$ \\ ${ }^{1}$ Universidad de Guanajuato, Lascurain de Retana 5, 36000 Guanajuato, GTO, Mexico \\ ${ }^{2}$ Departamento de Fisiología, Biofísica y Neurociencias, CINVESTAV, Avenida Instituto Politécnico Nacional 2508, \\ San Pedro Zacatenco, Gustavo A. Madero, 07360 Ciudad de México, DF, Mexico \\ Correspondence should be addressed to Myrna Sabanero-López; myrna@ugto.mx
}

Received 25 June 2014; Revised 10 October 2014; Accepted 13 October 2014; Published 12 November 2014

Academic Editor: Takao Yagi

Copyright (C) 2014 Lérida Liss Flores Villavicencio et al. This is an open access article distributed under the Creative Commons Attribution License, which permits unrestricted use, distribution, and reproduction in any medium, provided the original work is properly cited.

\begin{abstract}
The effects of organic and inorganic forms of selenium (Se) on human cells have been extensively studied for nutritional concentrations; however, to date, little is known about the potential toxicity at supranutritional levels. In the present study we determined the effects of sodium selenite (SSe) and selenomethionine (SeMet) on cell growth and intracellular structures in lung cancer cells exposed at Se concentrations between 0 and $3 \mathrm{mM}$. Our results showed that SSe affected cell growth more rapidly than SeMet $(24 \mathrm{~h}$ and $48 \mathrm{~h}$, resp.). After $24 \mathrm{~h}$ of cells exposure to $0.5,1.5$, and $3 \mathrm{mM} \mathrm{SSe}$, cell growth was reduced by 10,50 , and $60 \%$, as compared to controls. After $48 \mathrm{~h}$, nuclear fragmentation was evident in cells exposed to SSe, suggesting an induction to cell death. In contrast, SeMet did not affect cell proliferation, and the cells were phenotypically similar to controls. Microtubules and microfilaments structures were also affected by both Se compounds, again SSe being more toxic than SeMet. To our knowledge, this is the first report on the differential effects of organic and inorganic Se in supranutritional levels in lung cancer cells.
\end{abstract}

\section{Introduction}

Selenium (Se), as part of selenoproteins, plays a major role in the metabolism of thyroid hormones and cellular protection against oxidative stress $[1,2]$. Selenoenzymes are needed for fetal cell differentiation, growth, and development [3] and Se deficiency results in decreased immunoglobulin production and activity of glutathione peroxidase, which reduces cell hydroperoxides [4]. Debate remains on the minimum required Se concentration in plasma for maximal expression of a variety of enzymes. For glutathione peroxidase $75 \mathrm{ng} / \mathrm{mL}$ is required, which can be achieved with an intake of $40 \mu \mathrm{g} / \mathrm{d}$ Se [5-7]. Selenoprotein activity maximizes with plasma Se levels between 1.2 and $1.7 \mu \mathrm{mol} / \mathrm{L}$ [8]. According to a study performed by Thomson [9], selenium concentration that can be achieved in blood to an optimum metabolism might depend on population type. The main sources for Se are cereals, meat, and fish, with milk and eggs providing smaller amounts $[10,11]$.

The effects of Se in living systems depend on the chemical structure of its compounds, which are in turn related to their concentration and bioavailability. For example, the bioavailability of selenomethionine (SeMet) is greater than that of sodium selenite (SSe) [12].

Even when high Se doses may be toxic [13, 14], supranutritional levels of this element exert protective effects against some diseases including hypertension and cancer [15-19]. Although the anticarcinogenic effects of Se have been demonstrated [20] to our knowledge, few studies compare the effects when different chemical forms of Se are supplied at supranutritional levels.

The present study was conducted by exposing human cancer cell line A-549ATCC to supranutritional organic and inorganic Se (up to $3 \mathrm{mM}$ ) in order to determine the effect 


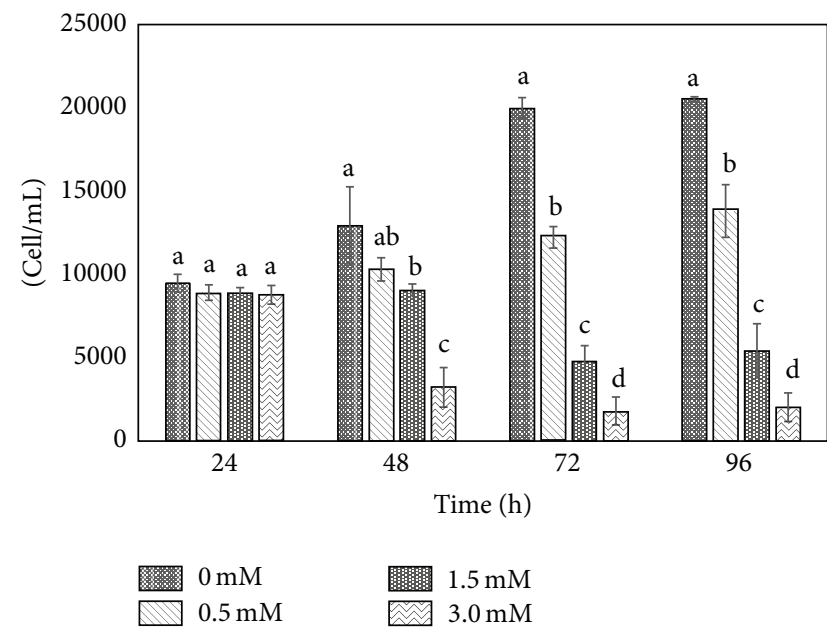

(a)

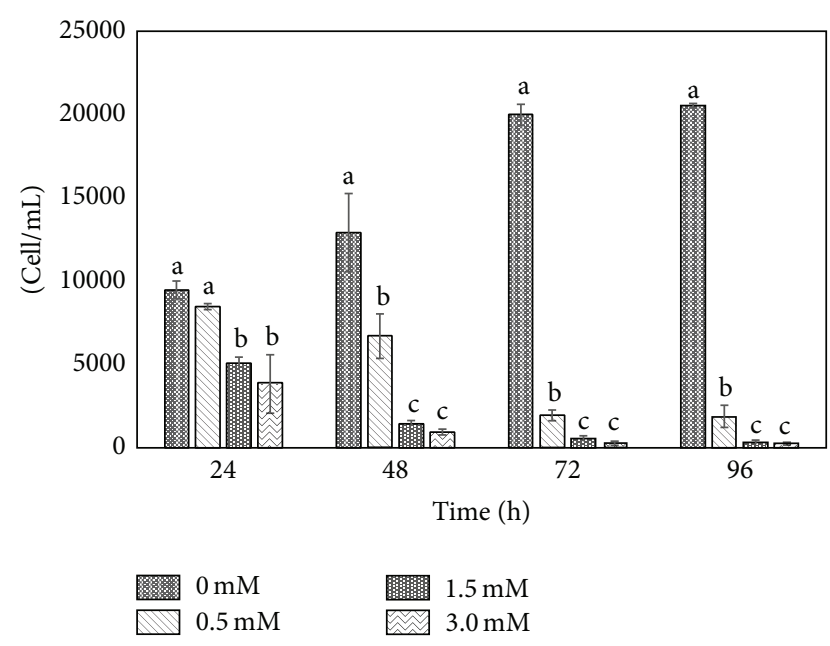

(b)

FIGURE 1: Cell growth of lung cancer cells exposed to 0; 0.5; 1.5; and $3.0 \mathrm{mM}$ Se supplied as (a) SeMet or (b) SSe for $96 \mathrm{~h}$. Values are the arithmetic mean \pm standard deviation $(n=3)$. Different letters show significant differences in cell growth between each concentration at the same time $(P<0.05)$.

on cell growth, DNA, and cytoskeletal structures. Our results suggest that $\mathrm{Se}$, administered at supranutritional concentrations to human lung cancer cells, can be further explored as an option for cancer treatment. The delivery might be performed via functionalized nanoparticles.

\section{Materials and Methods}

2.1. Chemicals. Seleno-L-methionine (SeMet) and sodium selenite (SSe) were purchased from Sigma (St. Louis, MO, USA). All other chemicals used in this study are commercially available.

2.2. Cell Culture. The human lung cancer cell line A-549 ATCC was selected for this study. The cells were cultivated in D-MEM (Dulbecco's Modified Eagle's Medium, GIBCO, USA) supplemented with fetal bovine serum 10\% (GIBCO, USA) and incubated at $37^{\circ} \mathrm{C}, 5 \% \mathrm{CO}_{2}$.

2.3. Exposure of A549 Cells to Selenium Compounds. Subconfluent cultures were prepared in 12-well plates (Costar, Corning, USA), which were exposed to either SSe or SeMet at Se concentrations of $0.5,1.5$, and $3 \mathrm{mM}$ for $24 \mathrm{~h}$. After exposure, the cell viability was determined by trypan blue. The experiments were performed in triplicate and the results reported as means \pm standard deviation (SD). Statistical analysis was performed by one-way analysis of variance. Tukey HSD (Honestly Significant Difference) was used as a post hoc test to determine significant differences between treatments $(P<0.05)$ and Minitab 17.0.1 software was used to perform data analysis.

2.4. Protein Profile Analysis. A549 cells were exposed to selenium compounds at a concentration of $0.5 \mathrm{mM}$ for $24 \mathrm{~h}$. Later, the cells were washed three times with PBS, solubilized with

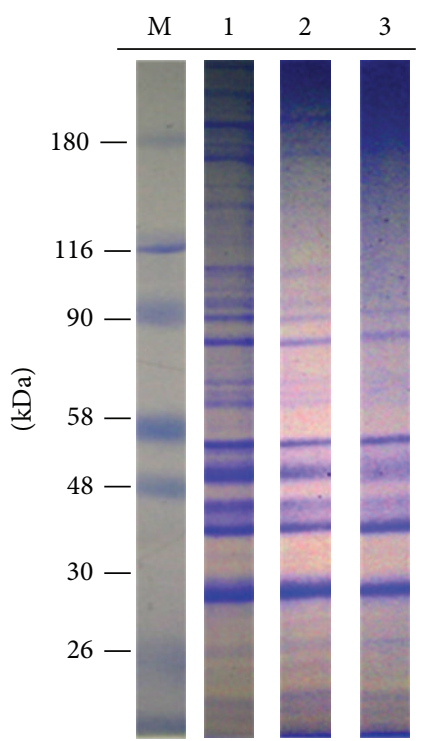

FIGURE 2: Protein profile of cells exposed to SeMet and SSe: controls (Lane 1) cells treated with $0.5 \mathrm{mM}$ SeMet (Lane 2) and SSe (Lane 3) for $48 \mathrm{~h}$; standard molecular mass markers $(\mathrm{M})$ are shown in the first lane.

$2 \%$ SDS plus inhibitor proteases cocktail (Roche, Germany). The samples $(40 \mu \mathrm{g} /$ lane $)$ were fractionated in SDS-PAGE $10 \%$ gel under reducing conditions [21] and stained with Coomassie Blue 0.25\% (Sigma, USA). Protein standards were used for reference (Sigma, USA).

2.5. Immunocytochemistry Analysis. Control cells and those exposed to selenium compounds were fixed with $4 \%$ pformaldehyde for $20 \mathrm{~min}$, permeabilized with $0.05 \%$ Triton buffer containing $10 \mathrm{mM}$ Tris, $5 \mathrm{mM} \mathrm{KCl}$, and $1 \mathrm{mM} \mathrm{MgCl}$, 


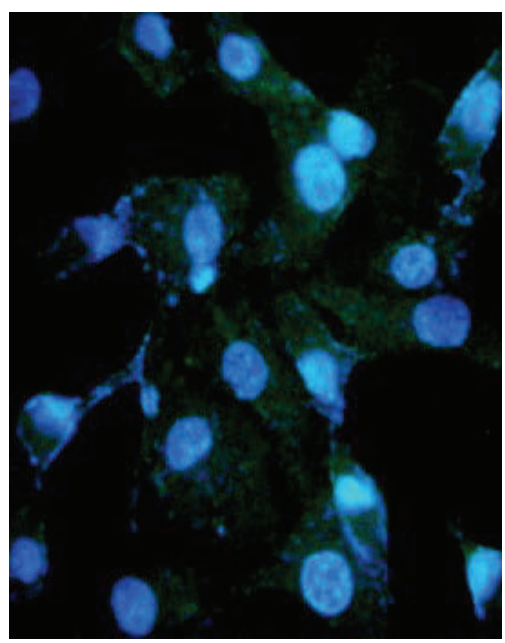

(a)

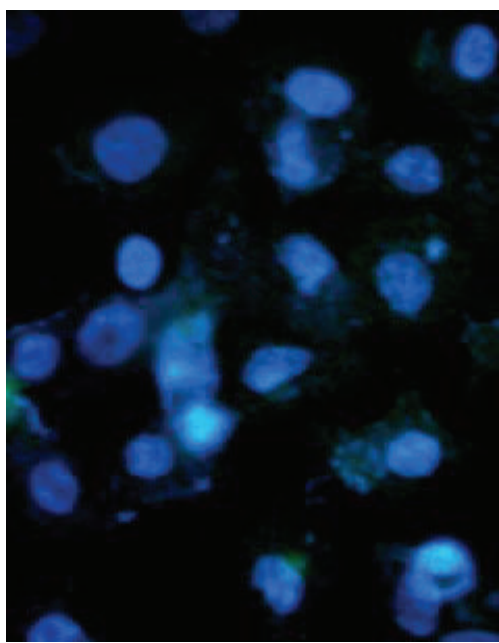

$\left(\mathrm{a}^{\prime}\right)$

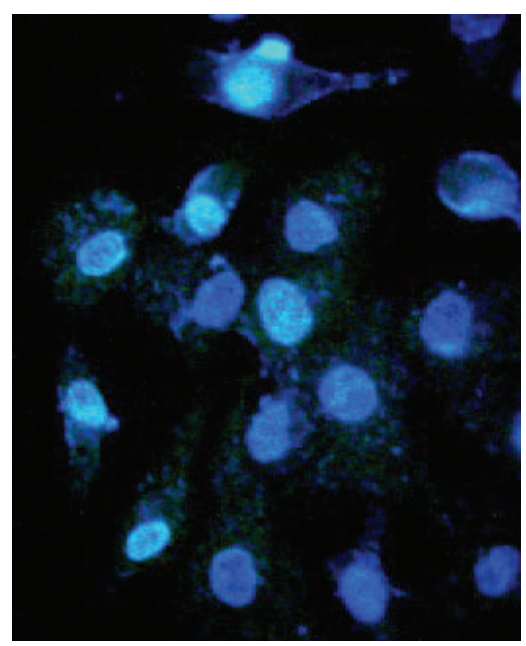

(b)

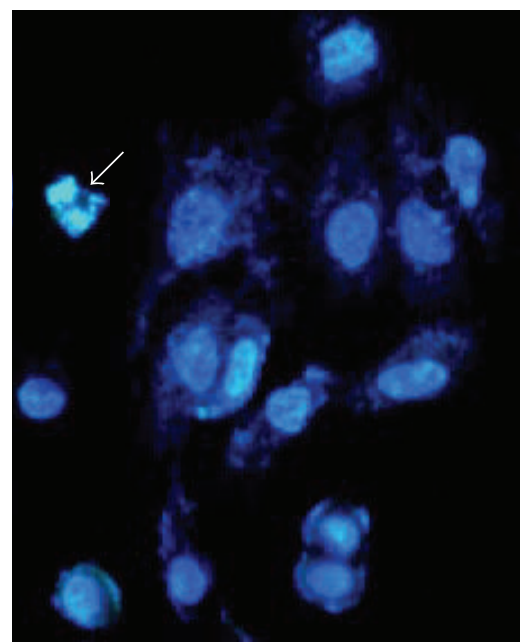

$\left(\mathrm{b}^{\prime}\right)$

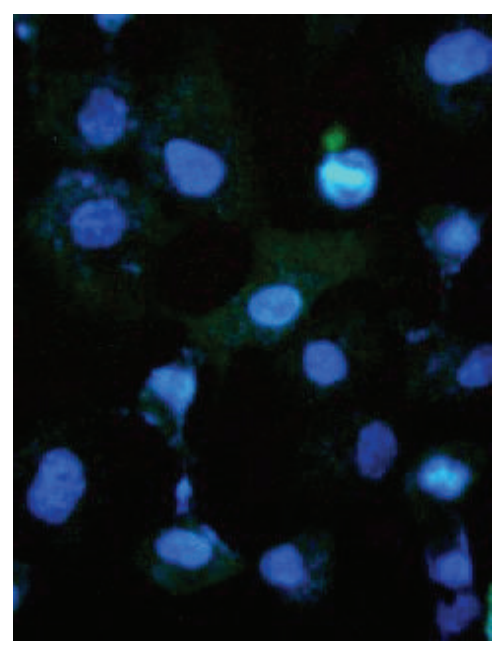

(c)

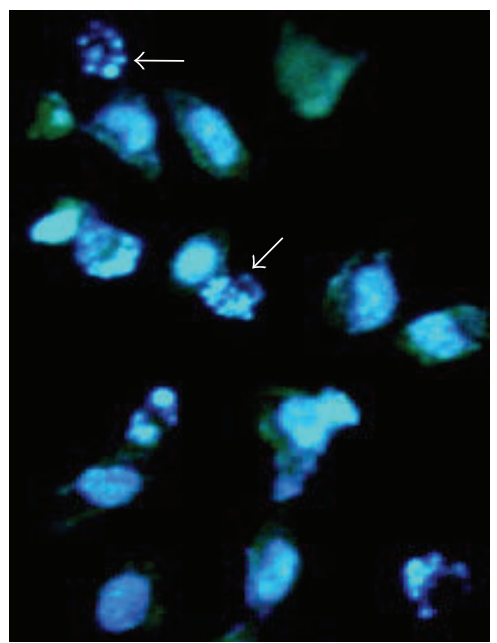

$\left(c^{\prime}\right)$

Figure 3: Nuclei of cells exposed to SeMet and SSe: controls (a and $\mathrm{a}^{\prime}$ ); cells exposed to 0.5 and $1.5 \mathrm{mM}$ Se as SeMet (b, c); cells exposed to 0.5 and $1.5 \mathrm{mM}$ Se as SSe $\left(\mathrm{b}^{\prime}, \mathrm{c}^{\prime}\right)$ for $48 \mathrm{~h}$. Arrows indicate nuclear fragmentation in SSe-treated cells.

and later exposed to anti- $\beta$-Tubulin/anti-mouse IgG-FITC antibodies or FITC-phalloidin (Sigma Aldrich). The preparations were mounted using Vecta Shield-DAPI (Vector Laboratories, USA) and observed under a fluorescence microscope (Leica, DMLS) using a 450-490 nm B filter.

2.6. DNA Preparation. The cells were exposed to selenium compounds as previously described. To perform the extraction of the cell culture, the medium was removed and $300 \mu \mathrm{L}$ of lysis buffer was added. Genomic DNA extraction was performed according to Sambrook et al. [22]. DNA samples were analyzed on $1.5 \%$ agarose gels and stained with ethidium bromide. The bands were visualized with UV light at 260$280 \mathrm{~nm}$ (Gene Genius, Syngene).

\section{Results}

3.1. Effect of Organic and Inorganic Selenium on Cell Growth. One-way analysis of variance was used to perform data analysis on cell growth. Tukey HSD (Honestly Significant Difference) was used as a post hoc test to determine significant differences between means in the different treatments $(P<$ 0.05 ) and Minitab 17.0.1 software was used to perform data analysis. Cell growth of lung epithelial cells exposed to SeMet and SSe is shown in Figures 1(a) and 1(b), respectively. At time $0 \mathrm{~h}$, every treatment was started with 6,165 cells $/ \mathrm{mL}$. Figure 1(a) shows no difference in cell growth between treatments (SeMet) at $24 \mathrm{~h}$ of exposure. However, after this point, significant differences $(P<0.05)$ in cell growth with respect to controls were observed, regardless of the concentration. At $48 \mathrm{~h}$, Se levels of $0.5,1.5$, and $3 \mathrm{mM}$ reduced cell growth reduction were in 10,30 , and $70 \%$, respectively $(P<0.05)$. The growth inhibition of SeMet after $96 \mathrm{~h}$ was similar to that at $72 \mathrm{~h}$, with values about 30,70 , and $90 \%$.

Differential results were obtained in lung epithelial cells treated with SSe (Figure 1(b)). Growth inhibition was observed at $24 \mathrm{~h}$ where 1.5 and $3.0 \mathrm{mM}$ Se significantly $(P<0.05)$ 


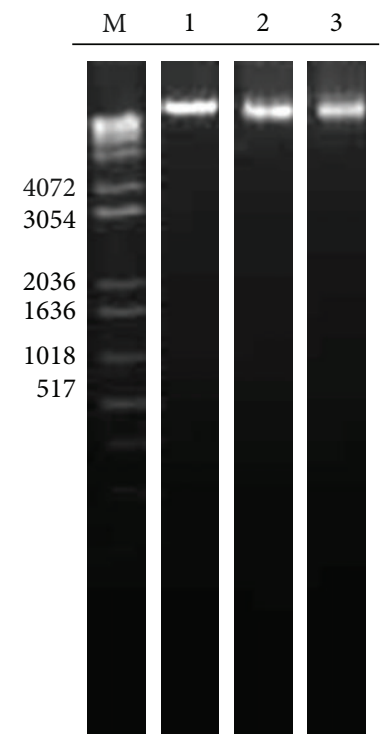

Figure 4: Genomic DNA of cells exposed to SeMet and SSe. M corresponds to the molecular markers (bp); controls (Lane 1); cells exposed to $0.5 \mathrm{mM}$ Se as SeMet (Lane 2); cells exposed to $0.5 \mathrm{mM} \mathrm{Se}$ as SSe (Lane 3).

decreased cell growth with respect to control by 45 and $60 \%$, respectively. After $24 \mathrm{~h}$, a trend in cell growth decrease was observed in every Se concentration supplied as SSe. Moreover, at 72 and $98 \mathrm{~h}$, the presence of SSe provoked a decrease of cell growth of more than $90 \%$. Thus, SSe exerted more toxic effects to cells than SeMet.

3.2. Protein Profile Analysis. Figure 2 shows the peptide profiles of control cells (Lane 1) and those treated with $0.5 \mathrm{mM} \mathrm{Se}$ supplied as either SeMet (Lane 2) or SSe (Lane 3). As observed in this figure, in controls (Lane 1), the major peptides with $\mathrm{MW} \geq 190,170,150,110,90,80,65,60,55,48,40,35$, and $28 \mathrm{kDa}$ are present. In contrast, the profiles of cells treated with SeMet and SSe show that peptides with $M W \geq 60$, $65,150,170$, and $190 \mathrm{kDa}$ decrease under SeMet and SSe treatment.

3.3. Nuclei Analysis. The nuclei of cells were stained with $4^{\prime}, 6$-diamidino-2-phenylindole (DAPI). In control nucleus (Figures 3(a) and 3( $\left.\mathrm{a}^{\prime}\right)$ ) was observed at fluorescence pattern homogeneous. Similar results were observed in the nuclei of cells treated with 0.5 and $1.5 \mathrm{mM}$ Se given as SeMet (Figures 3 (b) and 3(c)). In contrast, some the nuclei of cells treated with 0.5 and $1.5 \mathrm{mM}$ Se in the form of SSe showed nuclear fragmentation (Figures $3\left(b^{\prime}\right)$ and $3\left(c^{\prime}\right)$ ). Results indicate that damage at the nuclear level by the SSe is dependent on concentration and suggests cell death induction. However, the genomic analysis of DNA (Figure 4) showed no alterations of this structure after treatment with either organic or inorganic selenium.

3.4. Microtubule Distribution. Microtubule distribution in cells treated with both selenium compounds was analyzed by immunocytochemistry after $48 \mathrm{~h}$ of exposure. Tubulin staining showed in control cells a microtubule pattern, where the microtubule network in the cytoplasm outlines the cell morphology (Figures 5(a) and 5( $\left.\mathrm{a}^{\prime}\right)$ ).

The cells treated with 0.5 and $1.5 \mathrm{mM}$ Se as SeMet (Figures 5(b) and 5(c)) showed that the fluorescence distribution is altered on the edges of the cell membrane. This alteration is more evident in cells exposed to the $1.5 \mathrm{mM}$ level (Figure 5(c)). A loss of fluorescence is also observed, in addition to cell morphology alterations.

The distribution of the microtubule network in cells treated with 0.5 and $1.5 \mathrm{mM}$ Se as SSe (Figures $5\left(\mathrm{~b}^{\prime}\right)$ and $5\left(\mathrm{c}^{\prime}\right)$ ) showed a severe alteration of the fluorescence patterns compared to control cells (Figures 5(a) and 5( $\left.\mathrm{a}^{\prime}\right)$ ). The concentration-dependent loss of morphology is evident (Figure $5\left(c^{\prime}\right)$ ) and there are a large number of rounded cells that retain fluorescence around the perinuclear region. The results indicate that the microtubular network was affected by both SeMet and SSe; however, this network is even more affected in cells exposed to SSe.

3.5. Microfilament Distribution. The actin microfilaments distribution was examined using phalloidin, which specifically binds to polymerized actin or F-actin. Control cells (Figure 6(a)) show typical microfilament bundles in the cytoplasm towards the plasma membrane. Fluorescence is also observed at the edges of intercellular junctions (Figure $6\left(\mathrm{a}^{\prime}\right)$ ). In cells exposed to SeMet at 0.5 and $1.5 \mathrm{mM}$ Se, fluorescent plaques appeared at the edges of the membrane (Figures 6(b) and 6(c)). In cells exposed to SSe at the same Se concentrations, the fluorescence showed to be distributed in the cytoplasm (Figures $6\left(b^{\prime}\right)$ and $6\left(c^{\prime}\right)$ ). No filamentous structures were observed and loss of extended cell shape was evident. Our results indicate that SeMet and SSe alter the microfilament arrangement, affecting cell morphology integrity in a concentration-dependent manner.

\section{Discussion}

The effects of inorganic Se, selenite, and selenate on cancer development have been widely analyzed [23, 24]. To a lesser extent, anticarcinogenic Se activity has been explored. Among the organoselenium compounds, SeMet has been extensively used to evaluate the anticarcinogenic activity because it is the main natural form of this element in foods [11]. However, few studies compare the performance of organic and inorganic Se.

Elemental speciation is strongly related to bioavailability and metabolic transformation. In the case of Se, the absorption of SSe (the inorganic form) is lower than that of SeMet (the organic form) [25]. High concentrations of SeMet produce toxic effects similar to those induced by inorganic Se [13].

Our results indicated that the effects of organic and inorganic forms of selenium on lung cancer cells were concentration and speciation dependent. Both compounds inhibited cell growth and induced changes in cytoskeleton organization and protein expression. In this context, the decrease of 


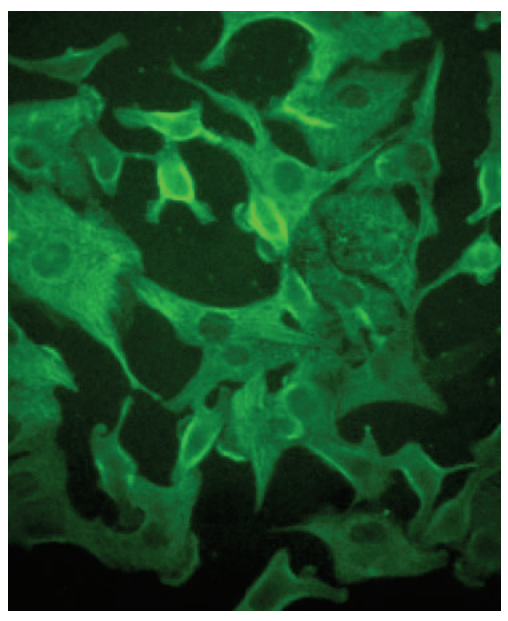

(a)

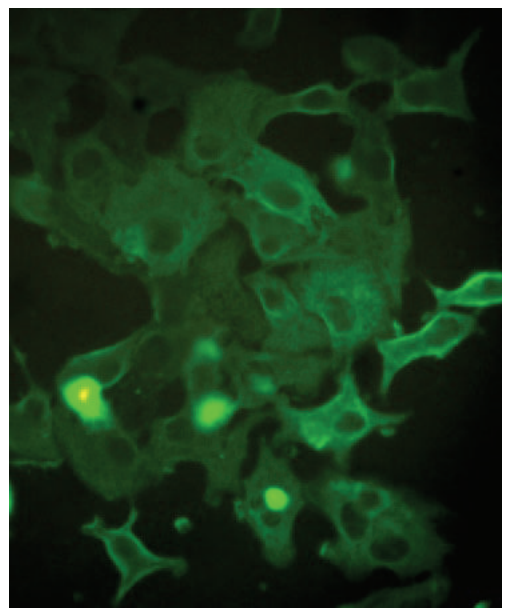

$\left(a^{\prime}\right)$

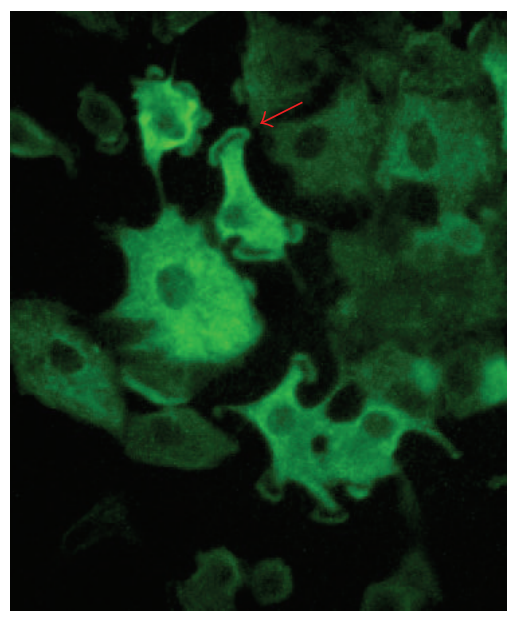

(b)

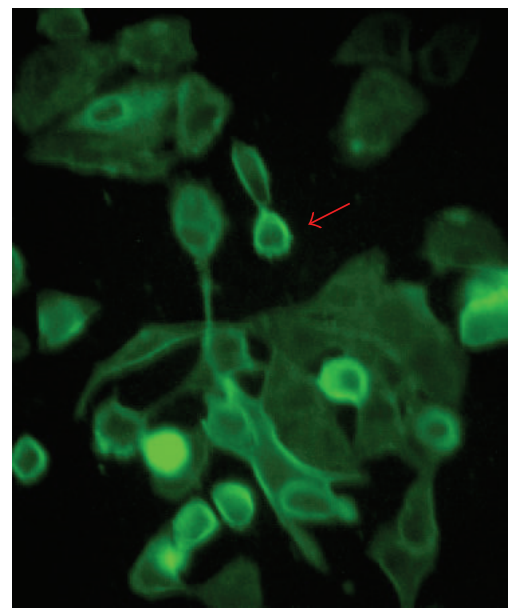

$\left(\mathrm{b}^{\prime}\right)$

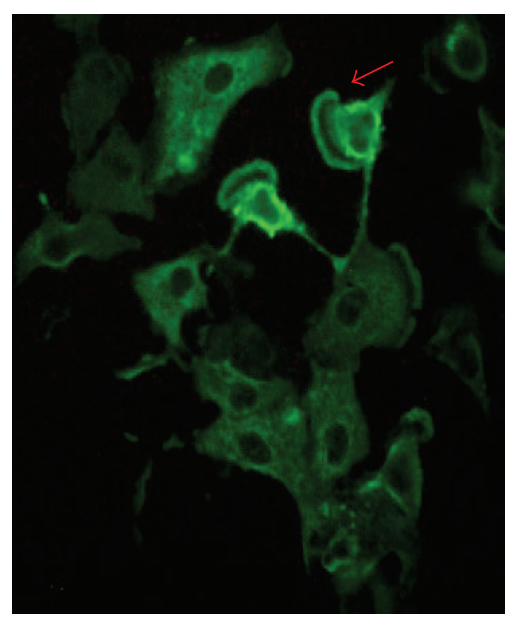

(c)

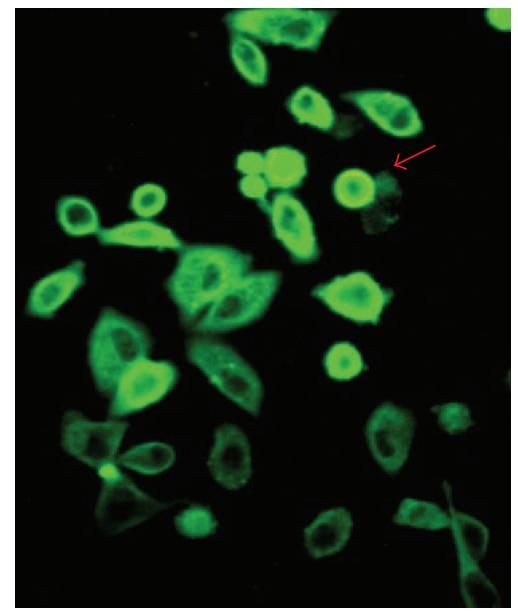

(c')

Figure 5: Microtubules of cells exposed to SeMet and SSe. Controls (a and $\mathrm{a}^{\prime}$ ); cells treated with 0.5 and $1.5 \mathrm{mM}$ Se as SeMet (b and c) and SSe $\left(b^{\prime}, c^{\prime}\right)$ for $48 \mathrm{~h}$. Arrows show changes in microtubule distribution and loss of morphology.

high molecular weight proteins can be the microtubules binding protein $(\mathrm{MBP})$ and/or the actin binding protein (ABP) [26]. In particular, the results evidence a dramatic change of fluorescent actin fibers consisting of F-actin patches decorating by FITC-phalloidin. In this regard, some ABP may be involved in the nucleation of these patches, as actinogelin [27] which induces gelation of F-actin; the protein consists of subunits of 112,000-115,000 daltons. Alternatively, other ABP as vinculin or $\alpha$-actinin can be involved [28]. This aspect is open to research.

In general, SSe produced more pronounced effects. Even when SSe is expected to be less bioavailable than SeMet, our results indicated that, at a same Se concentration, SSe was more toxic to the cells.

The essential nutritional importance of Se is due to its antioxidant action through enzymes such as glutathione peroxidase and thioredoxin reductase involved in the protection against damage produced by reactive oxygen species $[2,24]$.
Cells adequately supplied with Se are less susceptible to the damage effects of endogenously or exogenously generated oxygen radicals, which may attack cellular DNA. These situations are valid when dealing with the preventive activity of Se. In our study, we used lung cancer cells. Our results on the DNA integrity showed no difference in DNA structure when cells were exposed to $0.5 \mathrm{mM}$ Se supplied as either SeMet or SSe.

Staurosporine (St) is a competitive inhibitor of protein kinases that binds to kinases with high affinity and little selectivity [29]. St has been considered a valuable tool for the study of apoptosis, in several cell types that implicate changes in cell morphology from a flat to a stellate shape and nuclear fragmentation [30-33]. For all the above, the St was used as control to support our results of nuclear fragmentation (Figure 3).

The results of the cells exposed to $20 \mathrm{uM}$ staurosporine for $20 \mathrm{~h}$ show nuclear fragmentation (DAPI) and morphological 


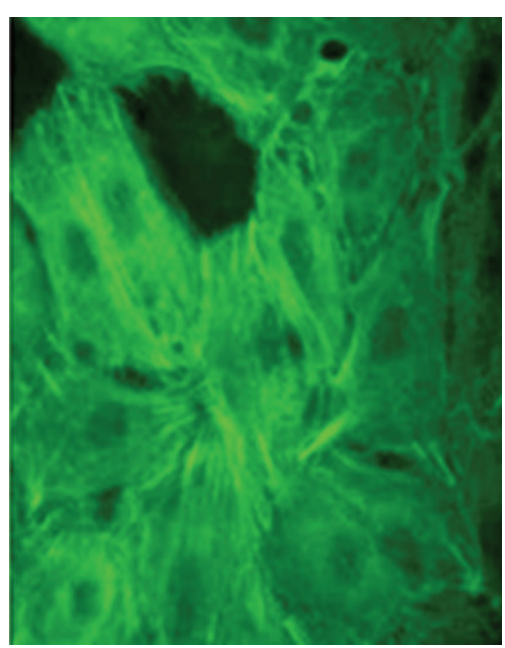

(a)

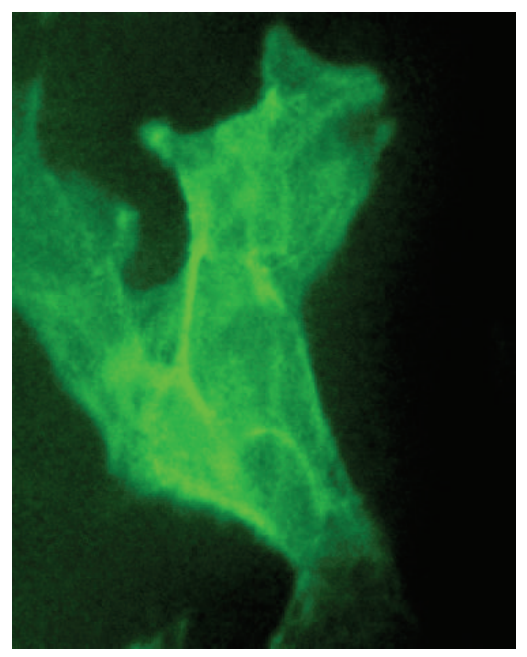

$\left(\mathrm{a}^{\prime}\right)$

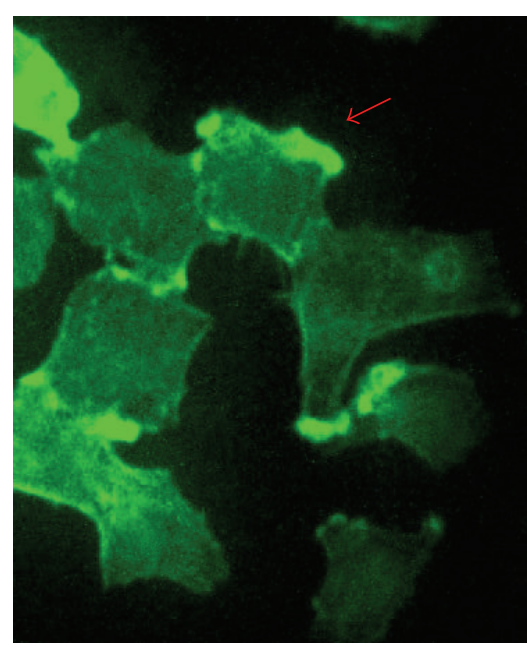

(b)

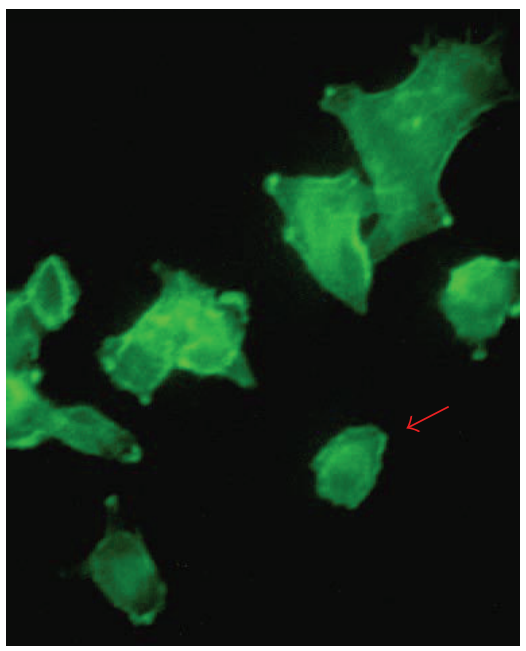

$\left(b^{\prime}\right)$

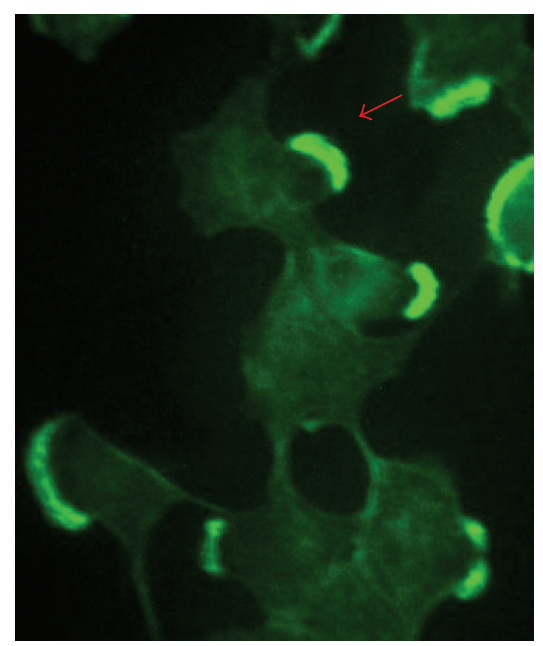

(c)

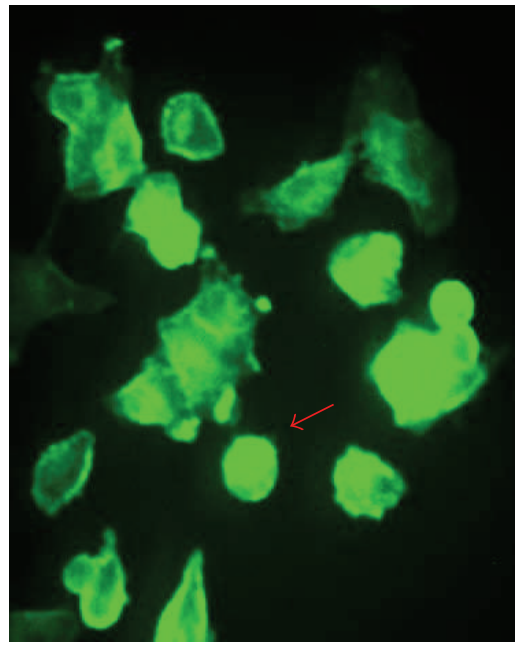

$\left(c^{\prime}\right)$

FIgure 6: Microfilaments of cells exposed to SeMet and SSe. Controls (a and $\mathrm{a}^{\prime}$ ); cells treated with 0.5 and $1.5 \mathrm{mM} \mathrm{Se}$ as SeMet (b and c) and $\mathrm{SSe}\left(\mathrm{b}^{\prime}, \mathrm{c}^{\prime}\right)$, respectively, for $48 \mathrm{~h}$. Arrows point to the fluorescent plates at the edges of the membrane and loss of spreading morphology.

changes characteristic of apoptosis with apoptotic bodies and altered distribution blebs actin (panel A: Figures 1(b) and $1\left(b^{\prime}\right)$, see Supplementary Material available online at http://dx.doi.org/10.1155/2014/923834).

Analysis of the genomic DNA shows DNA integrity and ribosomal RNA degradation compared to control cells not exposed to staurosporine (Supplementary Material, Figure 1(b)). However, $90 \%$ of the cells showed fragmentation (Supplementary Material, Figure 2(a)), unchanged at electrophoretic pattern of DNA that usually occurs in classical apoptosis. Given this, the results of nuclear fragmentation and DNA integrity with SSe and SeMet are not "artifacts" (Figures 3 and 4).

This reflects that classical apoptosis is not present, despite the fact that the inherent morphological alterations of an apoptotic cell, that is, altered distribution of actin, formation blending, alternatively can be induced by antiapoptotic molecules and activate mechanisms to recover cell homeostasis [34].

Our results differ with those reported by Menter et al. [35] who observed DNA fragmentation of prostate cancer cells treated with SeMet or SSe. This provides additional evidence on the dependence of Se action on cell type.

The high cytotoxicity of inorganic Se reported in the literature [36] is also observed in this study. Our results do not agree in the case of SeMet, the organic compound, which only showed minor cytoskeleton reorganization.

Cellular structures such as microtubules and microfilaments are involved in vital functions such as motility, secretion, and mitosis. Thus, the dynamics of these structures are essential in normal cell physiology [37-39]. For this reason, a variety of antitumor agents with action on microtubules have been developed [20]. The results of our study indicated that both SeMet and SSe affected the microtubular and 
microfilament network. Damage is more evident in cells exposed to SSe. Shi et al. [20] demonstrated that SSe disrupted microtubule assembly on leukemic HL60 cells but no data was found on the effects of SeMet on this type of cell.

According to our results, SSe may be used for the therapeutic treatment of cancer; however, one challenge would be to determine the proper via for SSe delivery to target cells. Recently, in glioma cell line, the alkylating agent temozolomide (TMZ) conjugated with selenium increased its potential as anticancer agent [40]. Moreover, chitosan stabilized selenium nanoparticles (Ch-Se NPs) were studied for this purpose. Estevez et al. [40] compared the effects of Ch-Se NPs and other Se compounds on hepatocarcinoma cells. According to their results, Ch-Se NPs are a novel compound for future applications as chemotherapeutic agent. Thus, the SSe may be delivered as NPs; however, further investigation should be performed.

\section{Conclusions}

This study showed a comparison among the effects of organic (SeMet) and inorganic Se (SSe) at supranutritional concentrations on lung epithelial cells. Inorganic Se was more effective in reducing cell growth and mechanism of action involving proteins, nuclear, microfilaments, and microtubule damage than those provoked by SeMet, even when SeMet is more bioavailable than SSe. If intended for the therapeutic treatment of cancer, SSe may be delivered through targeted nanoparticles directed to cancer cells.

\section{Conflict of Interests}

The authors declare that there is no conflict of interests regarding the publication of this paper.

\section{Acknowledgments}

The authors acknowledge financial support from Universidad de Guanajuato (Dirección de Apoyo a la Investigación y Posgrado), CONACYT, and PROMEP. This work was mainly performed at the Cell Biology Laboratory at Universidad de Guanajuato.

\section{References}

[1] M. Tolonen, "Finnish studies on antioxidants with special reference to cancer, cardiovascular diseases and aging," International Clinical Nutrition Review, vol. 9, pp. 68-75, 1989.

[2] A. Gallegos, M. Berggren, J. R. Gasdaska, and G. Powis, "Mechanisms of the regulation of thioredoxin reductase activity in cancer cells by the chemopreventive agent selenium," Cancer Research, vol. 57, no. 21, pp. 4965-4970, 1997.

[3] B. M. Y. Leung, B. J. Kaplan, C. J. Field et al., "Prenatal micronutrient supplementation and postpartum depressive symptoms in a pregnancy cohort," BMC Pregnancy and Childbirth, vol. 13, article 2, 2013.

[4] J. W. Finley, "Bioavailability of selenium from foods," Nutrition Reviews, vol. 64, no. 3, pp. 146-151, 2006.

[5] G. F. Combs, "Selenium in global food systems," British Journal of Nutrition, vol. 85, no. 5, pp. 517-547, 2001.
[6] P. R. Trumbo, “The level of evidence for permitting a qualified health claim: FDA's review of the evidence for selenium and cancer and vitamin E and heart disease," Journal of Nutrition, vol. 135, no. 2, pp. 354-356, 2005.

[7] M. Navarro-Alarcon and C. Cabrera-Vique, "Selenium in food and the human body: a review," Science of the Total Environment, vol. 400, no. 1-3, pp. 115-141, 2008.

[8] M. Persson-Moschos, W. Huang, T. S. Srikumar, B. Akesson, and S. Lindeberg, "Selenoprotein P in serum as a biochemical marker of selenium status," Analyst, vol. 120, no. 3, pp. 833-836, 1995.

[9] C. D. Thomson, "Assessment of requirements for selenium and adequacy of selenium status: a review," European Journal of Clinical Nutrition, vol. 58, no. 3, pp. 391-402, 2004.

[10] J. Neve, "Human selenium supplementation as assessed by changes in blood selenium concentration and glutathione peroxidase activity," Journal of Trace Elements in Medicine and Biology, vol. 9, no. 2, pp. 65-73, 1995.

[11] J. Falandysz, "Selenium in edible mushrooms," Journal of Environmental Science and Health Part C: Environmental Carcinogenesis \& Ecotoxicology Reviews, vol. 26, no. 3, pp. 256-299, 2008.

[12] R. F. Burk, B. K. Norsworthy, K. E. Hill, A. K. Motley, and D. W. Byrne, "Effects of chemical form of selenium on plasma biomarkers in a high-dose human supplementation trial," Cancer Epidemiology Biomarkers and Prevention, vol. 15, no. 4, pp. 804-810, 2006.

[13] G. N. Schrauzer, "Anticarcinogenic effects of selenium," Cellular and Molecular Life Sciences, vol. 57, no. 13-14, pp. 1864-1873, 2000.

[14] A. Pinto, D. T. Juniper, M. Sanil et al., "Supranutritional selenium induces alterations in molecular targets related to energy metabolism in skeletal muscle and visceral adipose tissue of pigs," Journal of Inorganic Biochemistry, vol. 114, pp. 47-54, 2012.

[15] G. Hocman, "Chemoprevention of cancer: selenium," International Journal of Biochemistry, vol. 20, no. 2, pp. 123-132, 1988.

[16] A. J. Duffield-Lillico, B. L. Dalkin, M. E. Reid et al., "Selenium supplementation, baseline plasma selenium status and incidence of prostate cancer: an analysis of the complete treatment period of the Nutritional Prevention of Cancer Trial," BJU International, vol. 91, no. 7, pp. 608-612, 2003.

[17] X. Zhou, W.-J. Ji, Y. Zhu et al., "Enhancement of endogenous defenses against ROS by supra-nutritional level of selenium is more safe and effective than antioxidant supplementation in reducing hypertensive target organ damage," Medical Hypotheses, vol. 68, no. 5, pp. 952-956, 2007.

[18] H. Zeng and G. F. Combs Jr., "Selenium as an anticancer nutrient: roles in cell proliferation and tumor cell invasion," Journal of Nutritional Biochemistry, vol. 19, no. 1, pp. 1-7, 2008.

[19] A. Holmstrom, R. T. Y. Wu, H. Zeng, K. Y. Lei, and W. H. Cheng, "Nutritional and supranutritional levels of selenate differentially suppress prostate tumor growth in adult but not young nude mice," Journal of Nutritional Biochemistry, vol. 23, no. 9, pp. 1086-1091, 2012.

[20] K. Shi, Q. Jiang, Z. Li et al., "Sodium selenite alters microtubule assembly and induces apoptosis in vitro and in vivo," Journal of Hematology \& Oncology, vol. 6, pp. 7-15, 2013.

[21] U. K. Laemmli, "Cleavage of structural proteins during the assembly of the head of bacteriophage T4," Nature, vol. 227, no. 5259 , pp. 680-685, 1970. 
[22] J. Sambrook, E. F. Fritsch, and T. Maniatis, Molecular Cloning: A Laboratory Manual, Cold Spring Harbor Laboratory, New York, NY, USA, 1989.

[23] P. R. Harrison, J. Lanfear, L. Wu, J. Fleming, L. McGarry, and L. Blower, "Chemopreventive and growth inhibitory effects of selenium," Biomedical and Environmental Sciences, vol. 10, no. 2-3, pp. 235-245, 1997.

[24] H. Zeng, J. J. Cao, and G. F. Combs Jr., "Selenium in bone health: roles in antioxidant protection and cell proliferation," Nutrients, vol. 5, no. 1, pp. 97-110, 2013.

[25] H. Y. Wen, R. L. Davis, B. Shi et al., "Bioavailability of selenium from veal, chicken, beef, pork, lamb, flounder, tuna, selenomethionine, and sodium selenite assessed in selenium-deficient rats," Biological Trace Element Research, vol. 58, no. 1-2, pp. 4353, 1997.

[26] S. J. Winder and K. R. Ayscough, "Actin-binding proteins," Journal of Cell Science, vol. 118, no. 4, pp. 651-654, 2005.

[27] N. Mimura and A. Asano, "Characterization and localization of actinogelin, a Ca2+-sensitive actin accessory protein, in nonmuscle cells," Journal of Cell Biology, vol. 93, no. 3, pp. 899-909, 1982.

[28] B. Geiger, K. T. Tokuyasu, A. H. Dutton, and S. J. Singer, "Vinculin, an intracellular protein localized at specialized sites where microfilament bundles terminate at cell membranes," Proceedings of the National Academy of Sciences of the United States of America, vol. 77, no. 7, pp. 4127-4131, 1980.

[29] M. W. Karaman, S. Herrgard, D. K. Treiber et al., "A quantitative analysis of kinase inhibitor selectivity," Nature Biotechnology, vol. 26, no. 1, pp. 127-132, 2008.

[30] T.-L. Yue, C. Wang, A. M. Romanic et al., "Staurosporine-induced apoptosis in cardiomyocytes: a potential role of caspase-3," Journal of Molecular and Cellular Cardiology, vol. 30, no. 3, pp. 495-507, 1998.

[31] A. J. Krohn, E. Preis, and J. H. M. Prehn, "Staurosporineinduced apoptosis of cultured rat hippocampal neurons involves caspase-1-like proteases as upstream initiators and increased production of superoxide as a main downstream effector," The Journal of Neuroscience, vol. 18, no. 20, pp. 81868197, 1998.

[32] M. D. Jacobson, M. Weil, and M. C. Raff, "Role of Ced-3/ICEfamily proteases in staurosporine-induced programmed cell death," Journal of Cell Biology, vol. 133, no. 5, pp. 1041-1051, 1996.

[33] H.-J. Chae, J.-S. Kang, J.-O. Byun et al., "Molecular mechanism of staurosporine-induced apoptosis in osteoblasts," Pharmacological Research, vol. 42, no. 4, pp. 373-381, 2000.

[34] S.-Y. Yang, L. Zhang, K.-K. Miao, W. Qian, and Z.-G. Zhang, "Effects of selenium intervention on chronic fluorosis-induced renal cell apoptosis in rats," Biological Trace Element Research, vol. 153, no. 1-3, pp. 237-242, 2013.

[35] D. G. Menter, A. L. Sabichi, and S. M. Lippman, "Selenium effects on prostate cell growth," Cancer Epidemiology Biomarkers and Prevention, vol. 9, no. 11, pp. 1171-1182, 2000.

[36] M. P. Rayman, "Selenium and human health," The Lancet, vol. 379, no. 9822, pp. 1256-1268, 2012.

[37] K. Baumann, "Cytoskeleton: nucleating actin," Nature Reviews Molecular Cell Biology, vol. 14, p. 67, 2013.

[38] R. David, "Cytoskeleton: a new partner for microtubules," Nature Reviews Molecular Cell Biology, vol. 14, no. 2, p. 67, 2013.

[39] Y. Cheng, U. H. Sk, Y. Zhang et al., "Rational incorporation of selenium into temozolomide elicits superior antitumor activity associated with both apoptotic and autophagic cell death," PLoS ONE, vol. 7, no. 4, Article ID e35104, 2012.

[40] H. Estevez, J. C. Garcia-Lidon, J. L. Luque-Garcia, and C. Camara, "Effects of chitosan-stabilized selenium nanoparticles on cell proliferation, apoptosis and cell cycle pattern in HepG2 cells: comparison with other selenospecies," Colloids and Surfaces B: Biointerfaces, vol. 122, pp. 184-193, 2014. 

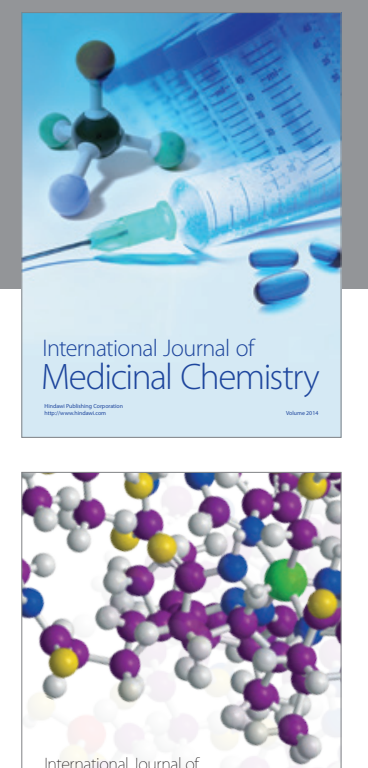

\section{Carbohydrate} Chemistry

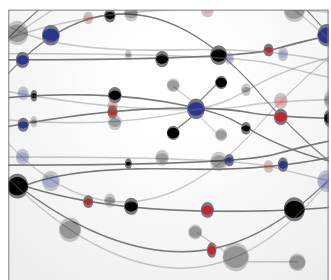

The Scientific World Journal
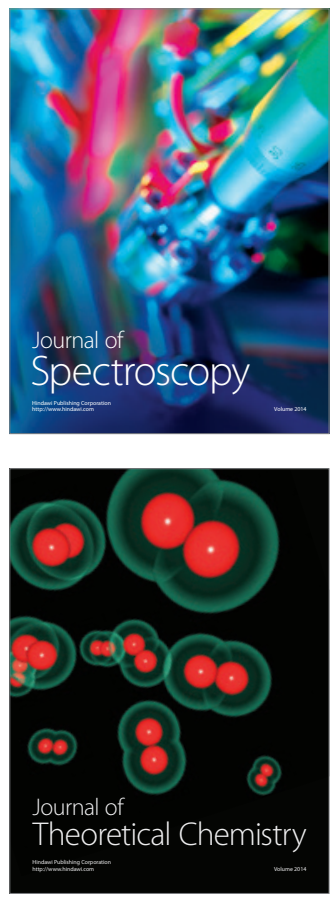
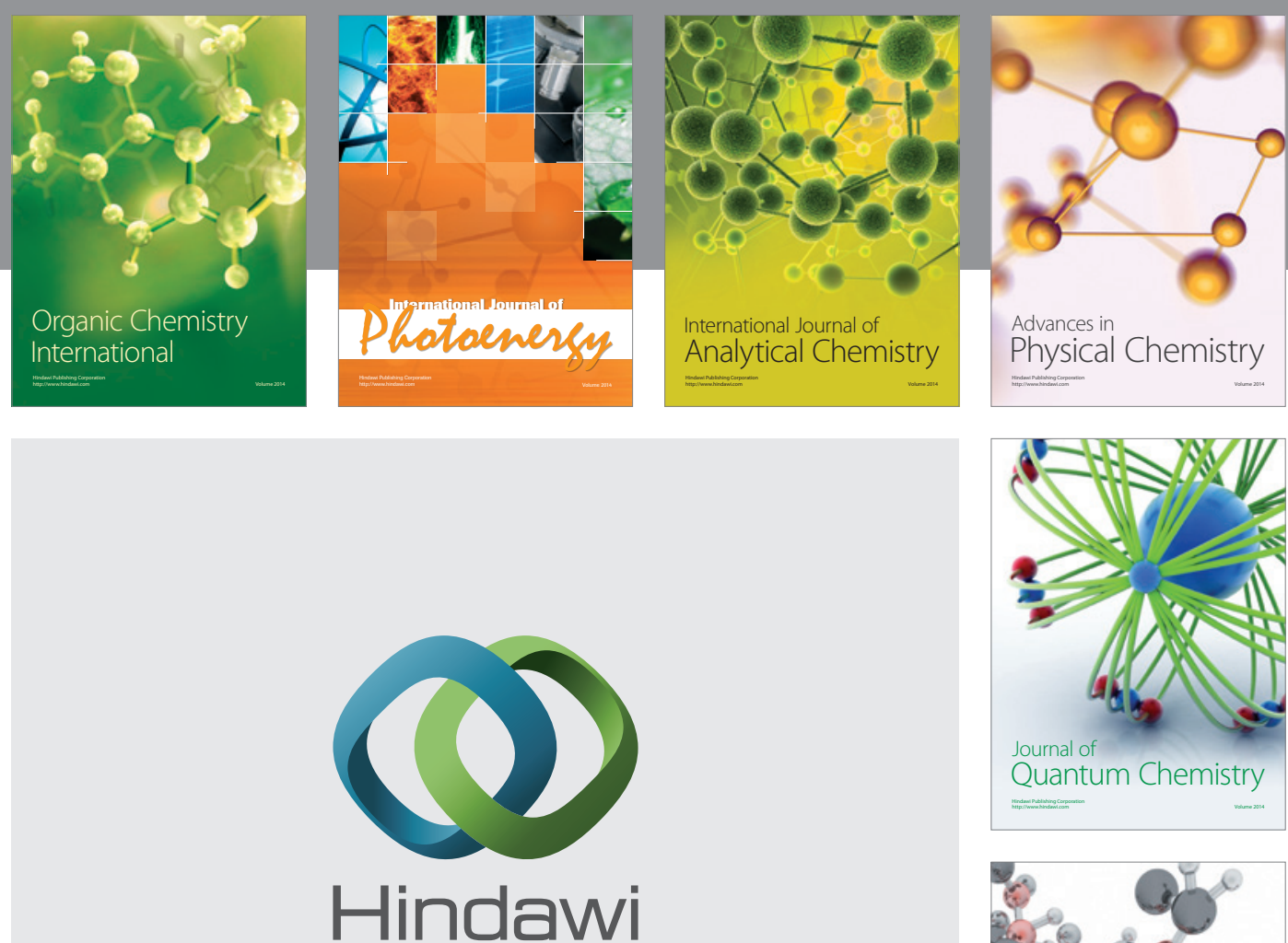

Submit your manuscripts at

http://www.hindawi.com

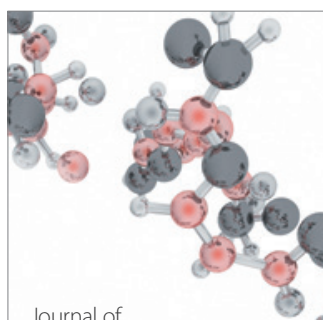

Analytical Methods

in Chemistry

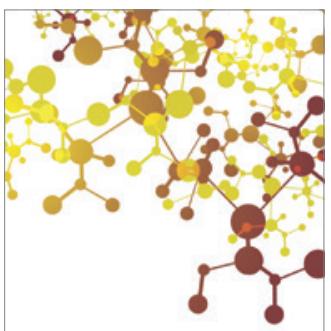

Journal of

Applied Chemistry

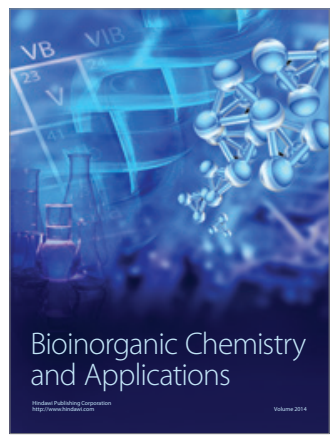

Inorganic Chemistry
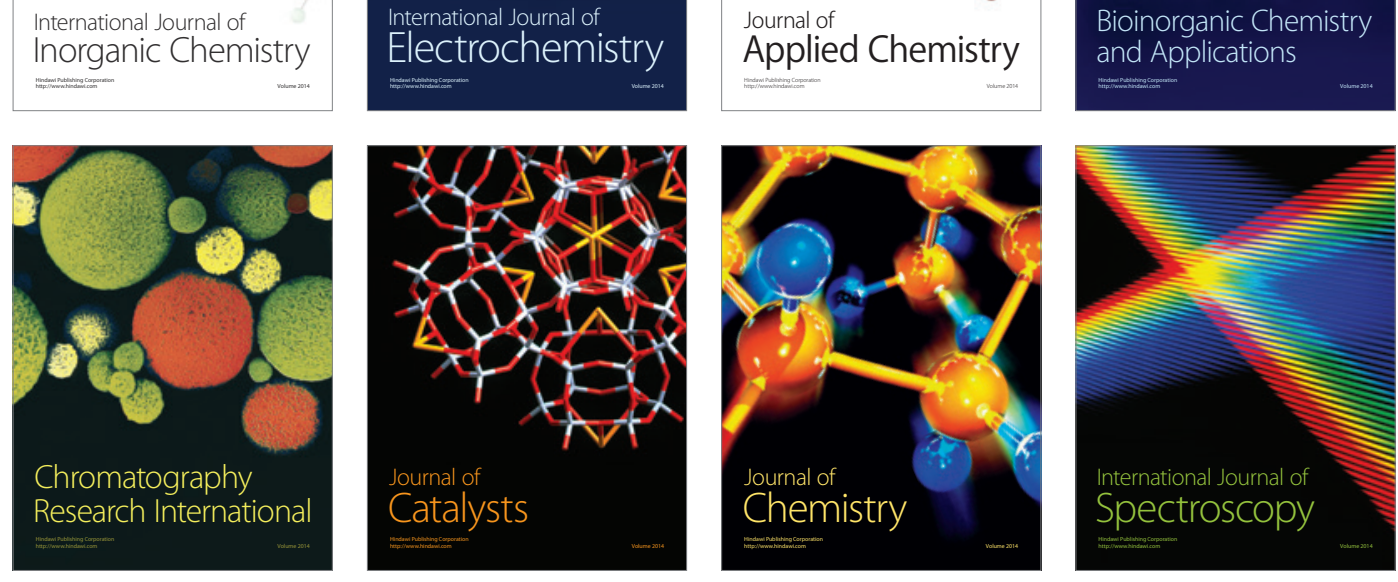